\title{
ALGUMAS CONSIDERAÇÕES SOBRE A AMBIGUIDADE DO CORPUS PAULINUM
}

Roberta Alexandrina da Silva ${ }^{1}$

\begin{abstract}
Resumo: Este artigo discute como os discursos foram apropriados e selecionados, com o intuito de legitimar posturas e comportamentos, acerca do passado cristão, as suas origens, em que o corpus paulinum se tornou um ponto de partida para debates e discussóes na atualidade. Portanto, este artigo sugere algumas concepções distintas para conceitos como feminino e masculino, analisados numa perspectiva de gênero. Emerge, dessa análise, outro olhar sobre o papel da sexualidade nas comunidades paulinas do I século e.c., o que permite um confronto dessa leitura com discursos acadêmicos sobre o assunto. Palavras-chave: Paulo; Cristianismo; comunidades; feminino; Ambiguidade; discursos.
\end{abstract}

Uma das figuras mais idiossincráticas do movimento cristão nos seus anos iniciais foi a de Paulo de Tarso. Para o teólogo James D. G. Dunn, na obra A Teologia do Apóstolo Paulo, a importância de Paulo de Tarso é ímpar, sendo o primeiro e o maior teólogo cristão (DUNN, 2003, p. 25). A afirmação do estudioso se baseia, sendo bem fundamentada, na influência dos escritos de Paulo sobre o cristianismo mais do que o fizeram os escritos e a teologia de qualquer outro pensador cristão.

A teologia paulina foi tão significante na formação da Igreja nos séculos posteriores que podemos perceber a sua influência em alguns momentos, tornando-se determinante na intuição, formação e transformações da consequente ortodoxia cristã. Desde a era patrística sua autoridade orientou sobre Clemente de Roma, Inácio de Antioquia e Irineu de Lyon na era patrística; na Antiguidade tardia, embasando o pensamento de Santo Agostinho propiciou que reafirma -se ou a teologia cristã que veio a dominar a maior parte da Idade Média; além disso, foram predominantemente o alcance da teologia de Paulo, por meio de releituras, que moldou a Reforma Protestante. E no período moderno alguns autores como F. C. Baur e Karl Barth atestam a mesma influência formativa.

1 Docente da Faculdade de História da cátedra de História Antiga e Medieval pela Universidade Federal do Pará, campus Universitário de Bragança. Docente do Programa de Pós-Graduação em Linguagens e Saberes na Amazônia e Professora associada do Laboratório de Estudos sobre o Império Romano - LEIR/UFES. E-mail: alexandrinasilva@yahoo.com.br 
Cada geração que refletiu sobre a teologia cristã influenciada pelos escritos paulinos desencadeou interpretações distintas. Para o historiador Bart D. Ehrman, isto ocorreu devido a figura de Paulo ser controversa, gerando extensos debates até hoje, principalmente quando são mencionados os ensinamentos alusivos aos comportamentos sexuais refletiu sobre a teologia paulina (EHRMAN, 2008, p.139).

Portanto, os escritos de Paulo pesam muito em qualquer debate, sobretudo, no concernente ao lugar da mulher na vida e no ministério da Igreja. Não seria exagero dizer que a literatura paulina se tornou o campo de combate do Novo Testamento, pois é onde se travam debates sobre os papéis das mulheres na Igreja (SHAW, 2004, p. 407).

Havendo assim demasiadas e extensas problemáticas entrelaçadas aos escritos paulinos, neste artigo aventarei algumas consideraçóes sobre as construções discursivas e a ambiguidade acerca de Paulo.

\section{A Ambiguidade Paulina: Misógino ou feminista?}

Simone de Beauvoir teve um papel importante no movimento feminista durante as décadas de 1960 e 1970, ao propalar a máxima que não se nasce mulher, se torna. Contudo, a crítica de Simone de Beauvoir não se restringiu à análise de que a categoria mulher é uma construção cultural e histórica, mas centrou-se, também, de que a religião auxiliou a opressão feminina na sociedade, ao declarar que:

A ideologia cristã não contribuiu pouco para a opressão da mulher. Há, sem dúvida, no Evangelho um sopro de caridade que se estende tanto às mulheres como aos leprosos; são os pequenos, os escravos e as mulheres que se apegam mais apaixonadamente à nova lei. Logo no início do cristianismo, eram as mulheres, quando se submetiam ao jugo da Igreja, relativamente honradas; testemunhavam como mártires ao lado dos homens; não podiam, entretanto, tomar parte no culto senão a título secundário; as diaconisas só eram autorizadas a realizar tarefas laicas: cuidados aos doentes, socorros aos indigentes. E se o casamento é encarado como uma instituição que exige fidelidade recíproca parece evidente que a esposa deve ser totalmente subordinada ao esposo: com são Paulo afirma-se a tradição judaica ferozmente antifeminista. São Paulo exige das mulheres discrição e modéstia; baseia, no Antigo e no Novo Testamento, o princípio da subordinação da mulher ao homem (BEAUVOIR, 1959, p. 118). 
Essa acepção de Simone de Beauvoir de que com Paulo afirma-se a tradição judaica ferozmente antifeminista, tem vários pontos questionáveis. Uma vez que, a autora não tinha conhecimento de que muitos dos textos atribuídos a Paulo foram escritos muito tempo depois de sua morte; sem contar um problema anacrônico, ao rotulá-lo de antifeminista.

A afirmação de Simone de Beauvoir, atualmente, é vista com certo receio. Entretanto, atualmente, ampliou-se o debate acerca da teologia paulina e seus escritos, mostrando vários pontos controversos e ambíguos.

A relação ambígua em vários trechos dos escritos paulinos apresenta uma indefinição do papel feminino dentro das comunidades, ocasionando debates e estudos tanto teológicos quanto das ciências humanas. De um lado temos estudos como de Elaine Pagels (1974, pp. 543-549), D. R. MacDonald (1986), Joël Delobel (1986, pp. 369-398) e John P. Meier (1978, pp. 212 226) argumentaram que Paulo propôs inferioridade feminina; do outro lado a maioria de teólogos como Morna D. Hooker (1963, pp. 410-416), Robin Scroggs (1972, pp. 283-303), Jerome Murphy O'Connor (1976, pp. 615-621) e Elisabeth S. Fiorenza (1992, pp. 153-166) consideraram que Paulo propóe a igualdade e reciprocidade entre homens e mulheres. Com isso, se percebe é que a relação de Paulo com as mulheres aparece assim como um problema de difícil resolução, porque incide numa posição binária que muitas vezes não contempla as especificidades que o corpus paulinum infere, pois tal discussão tende a ficar dispersa em extensa lista de periódicos, ou senão simplesmente constitui parte de monografias, com análise ampla demais.

Sem dúvida, o material paulino sobre a mulher ganha sobremaneira com o estudo de In Memory of Her de Elisabeth Schüssler Fiorenza. O material paulino recebe a análise e a reflexão crítica da obra de Elisabeth S. Fiorenza (1992) tão substancial e abrangente que a discussão hermenêutica ocupa os três primeiros capítulos do seu trabalho. Empregando modelo crítico feminista de interpretação, hermenêutica feminista de suspeita, Fiorenza visou reconstituir a história cristã primitiva enquanto história das mulheres, resgatar as características do 'original discipulado de iguais' e a parceria na missão daí decorrente, a fim de delinear o deslocamento gradual das lideranças das mulheres para o domínio masculino; sob a influência de tendências androcêntricas que, enfim, moldaram todo o registro escrito contido no Novo Testamento. A pretensão da autora não é simplesmente restituir as histórias das mulheres à história cristã primitiva, mas permitir o resgate dos testemunhos igualitários no Novo Testamento, para novamente reacender uma visão e práxis cristãs não-patriarcais.

O debate sobre a atitude e Paulo com as mulheres intensifica-se quando, no início da década de 1970, o movimento feminista, em especial as teólogas 
feministas, inicia estudos aos textos neotestamentários. Concomitantemente com os severos ataques à influência de Paulo, surgem na época inúmeros estudos que procuraram atribuir credencias feministas, nesse sentido o trabalho de Elisabeth S. Fiorenza se torna pioneiro.

Paralelamente, temos o trabalho de D. R. MacDonald, na obra There is no male and female, em que distingue o teor singularmente igualitário da afirmação do locus classicus de Gálatas 3,23-29 e a distorção que houve nos escritos subsequentes, especialmente, nas Cartas pastorais (MACDONALD, 1986, pp. 2-5). É uníssono entre os estudiosos que as Cartas Pastorais - 1 e 2 Timóteo, Tito e Efésios - não são criação de Paulo, entretanto, são composições que surgiram em período tardio.

A exclusão do material pós-paulino torna bem mais fácil o trabalho dos que procuram detectar em Paulo uma atitude positiva. Ainda assim, restam duas passagens problemáticas, na primeira Carta aos Coríntios: a declaração sobre a veste das mulheres (1 Cor 11,2-16) e a exortação ao silêncio na assembleia (1 Cor 14,33-36).

Entretanto, há um grande número de estudiosos, que consideram a segunda passagem uma interpolação no texto por escrito tardio, o qual teria grande afinidade com o autor das Cartas pastorais. Assim, dependendo da interpretação que se dê a 1 Cor 11,2-16, é que se julgou se Paulo declinou ou não do 'ideal igualitário' expresso em $\mathrm{Gl}$ 3,28.

De acordo com Mary Daly há uma questão importante que tem que ser ponderado quando se analisa o corpus paulinum consiste na visão que vários estudiosos e, em especial teólogas feministas, inferem ao tentar entender 'the real Paul. Para a autora o "Paulo real" para essas teólogas feministas não era o autor de passagens contra as mulheres e não era "all time male chauvinist". A autora faz a seguinte argumentação:

From the point of view of scriptural scholarship the distinction between the deutero-pauline authors and "the real Paul" is important, no doubt. However, the discussion is hardly central to women's concern with the oppressiveness of patriarchal religion. The point is that for nearly two thousand years the passages have been used to enforce sexual hierarchy. They represent an established point of view (DALY, 1973, p. 5).

$\mathrm{O}$ interessante que muitos desses trabalhos onde reforçam uma diferenciação entre o 'Paulo real' e o 'Paulo não real', consiste na metodologia empregada por esses estudiosos, o método histórico-crítico. 
O método histórico-crítico, do qual faz uso a maioria dos exegetas, parte da noção de que o conhecimento histórico-crítico é imanente, deve buscar a imparcialidade e adota como objetivo, na análise dos textos, a reconstrução do contexto histórico no qual eles foram produzidos (em nosso caso, a reconstrução dos primeiros momentos da história cristã). Esses pressupostos do método histórico-crítico se coadunam com a epistemologia e método que a História, como ciência, se compõe no século XIX.

Em contrapartida, ainda, temos a questão política em voga em certos trabalhos, como no caso de Elisabeth S. Fiorenza, que segundo Mary Jo Weaver (1995) não critica os fundamentos básicos dos seus pressupostos heurísticos nem a motivação ideológica por detrás de sua justificava em realizar um passado glorioso das mulheres sem criticar o ethos religioso de que faz parte.

Depois desse breve e conciso debate acima, torna-se imprescindível anuir que o movimento cristão, nos seus primórdios, não foi coeso; todavia, foram comunidades multiformes e heterogêneas localizadas ao longo de várias cidades do Mediterrâneo, onde eram marcados por várias tensões entre lideranças. O tipo de movimento propalado por Paulo de Tarso foi mais um dentre vários que existiram, estes ficaram no esquecimento; mas os escritos paulinos permaneceram e tornaram-se a expressão máxima do cristianismo e embates ao longo de geraçóes

Portanto, analisar o corpus paulinum no contexto de que verso, primeiro século e início do segundo, é desconstruir, também, um movimento paulino mostrando subjetividades, paulinismos, e a fluidez que foi o cristianismo, cristianismos antigos.

\section{Os Códigos Domésticos e os Valores Culturais de Honra E Vergonha}

Para Wayne Meeks (1992, p. 25), devemos nos remeter a Aristóteles para compreender os elementos da estruturação comunal cristã nos séculos iniciais. Os moralistas da fase inicial do império buscaram formular uma ética que equilibrasse as exigências tradicionais de subordinação e obediência ao paterfamilias e os ideais de igualdade formulados na época helenística (FIORENZA, 2004, p. 233).

Para Elisabeth S. Fiorenza, a misoginia ocidental tem raízes nos tratados aristotélicos, A Política e a Ética de Nicômaco, ao naturalizar os papeis sexuais e sociais, ao definir a unidade doméstica como modelo do Estado. A família está na ordem, de acordo com essa visão, quando funciona com o microcosmo 
da polis (Política, I. 1253b). Assim como os homens sobrepõem às mulheres no espaço doméstico, assim também se sobrepõem os governantes legítimos a seus súditos na pólis (Política, I. 1260a).

Segundo a análise aristotélica a pólis visa o bem maior, pois abrange outras comunidades menores e possui uma autossuficiência que as comunidades maiores não alcançam. O componente inicial é a família (oíkos), com as relaçóes entre marido e esposa, pais e filhos, senhores e servos. Portanto, a pólis compreendia tudo, desde o ato de governar dentro do oíkos (casa), a relação do marido e da esposa, filhos e escravos, até o governo dos cidadãos (Política, I. 1253B).

Não é à toa que na epígrafe Aristóteles definiu o homem grego com a famosa expressão (o homem é um animal por natureza político). E, com esta expressão, pretendeu afirmar a distinção do grego em relação aos outros homens pelo fato de viverem no seio dessa forma superior de organização que é a pólis.

Nesse sentido, a linguagem missionária de Paulo dentro das comunidades no Mediterrâneo não pareceu tão distintivamente religiosa a seus contemporâneos no Império Romano. $\mathrm{O}$ termo que ele usa para o movimento como um todo, assim como para comunidades particulares, ekklēsía, era primordialmente político, designação semelhante à ekklēsía (assembleia) de cidadãos da pólis grega. As assembleias de Paulo eram tanto políticas como religiosas, um tanto à maneira como o era a pólis grega. A compreensão de alguns códigos morais e a própria estrutura da Igreja durante período inicial parte, em especial, da análise de alguns elementos imbricados na pólis (ALEXANDRINA-SILVA, 2010, p. 180).

Com esse debate acima, reforço outro ponto imbricado: a questão sobre honra e vergonha nas sociedades mediterrânicas. Pois, observo que as estruturas que foram forjadas os preceitos e prescrições que os códigos domésticos foram elaborados. Ou seja, a delimitação entre os espaços do público e do privado, espaço dos homens e das mulheres, inseridos em vários documentos. Definindo padrões de masculinidade e feminilidade.

Para Philip F. Esler, um valor central no Mediterrâneo moderno é a concepção de honra, que é entendida como um sentido próprio de valor e de corroboração de compreensão por um grupo relevante. Para Philip F. Esler a oposição de honra é a noção de vergonha, adquirindo múltiplas colorações em diferentes regiões no Mediterrâneo. Segundo o autor:

Honour can either be ascribed (taht is, simply attributed to a person by virtue of birth or position) or achieved (that is, actively gained from 
another in various social arena in forms of interaction described as the pattern of challenge-and-response). The desire to obtain honor motivates Manu interactions between individuals and the groups whom they represent (ESLER, 2000, p. 16)

Esses conceitos advêm da antropologia cultural que está essencialmente preocupada com a compreensão transcultural e comparativa das pessoas em grupos de estrangeiros, especialmente em termos de como eles diferem de nós e do nosso grupo social.

Para o estudo sobre esses conceitos algumas obras são fundamentais como de J. G. Peristiany, na obra Honra e Vergonha, que analisa os valores e estruturas sociais do Mediterrâneo atual; sendo essencial para o estudo de Bruce Malina, em O Evangelho Social de Jesus - O Reino de Deus em perspectiva Mediterrânea, em que as informações comparativas sobre grupos sociais do Mediterrâneo atual ajudam a estabelecer as dimensões de cenários 'possíveis' e até mesmo 'prováveis', visto que, descrevem exemplos e casos aproximados que podem servir como um controle negativo da interpretação costumeira (MALINA, 2004, p. 17). Trabalhos de Julian Pitt-Rivers (1961) e de John Davis (1977) aludem que grupos mediterrâneos tradicionais atuais veem o mundo amplamente em termos de divisão sexual do trabalho enraizada nas concepções de honra e vergonha e que a pesquisa histórica confirma a presença deste cenário em registros textuais tanto em Homero, quanto no Antigo Testamento, em suma, no mundo greco-romano. De acordo com Jerome Neyrey (1998), é grande a probabilidade de que esta forma peculiar de divisão sexual do trabalho e da sociedade estivesse presentes nos tempos do Novo Testamento.

É nesse sentido, que questiono, ao mesmo tempo, essas estruturas fixas. Torna-se válido mencionar alguns debates nesse mundo greco-romano que quebram com a homogeneização do ser homem e do ser mulher. Quando mulheres mostravam certos tipos de comportamentos presumivelmente próprios dos homens por 'natureza', eram consideradas masculinas. Temos alguns exemplos de autores tanto gregos quanto romanos de atitudes masculinas que eram atribuídas às mulheres. Na obra de Ésquilo, Agamenon, Clitemnestra é descrita como uma mulher de grande inteligência, que por isso tinha atributos masculinos. Salústio, na obra Catilina, dá uma descrição detalhada da aristocrata Semprônia, que é criticada tanto por sua conexão com o conspirador Catilina como por sua falta de inibição:

Ahora entre estas mujeres estaba Sempronia, quien a menudo cometió muchas faltas de osadia masculina. Esta mujer era bastante afortunada 
con su familia $y$ su aspecto, y especialmente con su marido $y$ sus hijos; había leido bastante literatura griega y latina, era capaz de tocar la lira y bailar con mucha más habilidad que la que cualquier mujer respetable bubiera necesitado tener, y era también habilidosa en otras actividades que eran carne y bueso de la vida de placer. Pero Ella apreciaba cualquier cosa antes que tener decoro y moralidad; pasarias un momento difícil determinando qué derrochó más, si su dineroo su reputación; su apetitos sexuales eran tan ardientes que tomo la iniciativa con los hombres mucho más frecuentemente que ellos la tomaron con Ella. Antes de la conspiración babia roto a menudo su palabra, no reconoció sus deudas, babia estado implicada en asesinato, y se bundió en los abismos de la depravación como resultado de su alto tren devida y sus pocos fondos. Incluso poseía unas fuerzas intelectuales que no son de ninguna manera desdeñable: la habilidad de escribir versos, decir chistes, hablar ya sea modesta, tierna o insolentemente; en una palabra, tenía mucho ingenio y encanto (SALÚSTIO, Catilina y Jugurta, 1954, p. 25).

Não somente Salústio, escritor do final da República, que possuímos uma figuração de uma mulher com características masculinas, outro escritor romano, como Juvenal, via essa inversão como danoso:

Aún más desesperante es la mujer que tan pronto se sienta al banquete pide conversar de poetas y de poesía, comparando a Virgilio con Homero: profesores, críticos, legisladores, subastadores - incluso otra mujer - no pueden decir palabra. Ella resuena de tal forma que creerias que todas las ollas y las cacerolas se estuvieran estrellando contra el suelo o que cada campana de la ciudad estuviere sonando. Ella sola, por si misma, bace tanto ruido como una tribu primitiva abuyentando a un eclipse. Debería aprender la lección de los filósofos: 'la moderación es necesaria incluso para los intelectuales.' Y si aún quiere aparecer educada y elocuente, deja su vestido como un hombre, ofrece sacrificios a los dioses de los hombres $y$ se baña en los baños de los hombres. Las esposas no deberian intentar ser oradores públicas; no deberían utilizar ardides retóricos; no deberían leer a todos los clásicos - deben existir algunas cosas que las mujeres no comprendan. Yo mismo no puedo entender a una mujer que puede citar las reglas de la gramática y nunca comete una falta y cita a confusos $y$ olvidados poetas - como si los hombres se preocupasen de tales cosas -. Si Ella tiene que corregir a alguien, permitasele corregir a sus amigas y deje a su marido en paz (JUVENAL, Sátiras, 6. 434-456).

Citei, alguns exemplos de vários que possuímos numa ampla literatura greco-latina, para mostrar a variedade de discursos que descrevem como para alguns autores os atributos sexuais não eram fixos. Em alguns textos, também, é possível realizar uma inferência em que demonstram atributos e qualidades 'femininas' do homem, tornando a identidade como algo fluído e não estanque. 
$\mathrm{Na}$ pesquisa de doutorado desenvolvido por Lourdes Feitosa, com o título de Amor e Sexualidade no Popular Pompeiano: Uma Análise de Gênero em Inscrições Paietais (2002), sobre as relações entre sexo e afeto nos grafites pompeianos, apontou que práticas sexuais que, em seu âmago estão relacionadas à sexualidade masculina e à feminina - a ação de future (foder) e de cunnun lingere (praticar a cunilíngua) -; temos exemplos de escritos em que essas relações eram invertidas. Como nas inscrições CIL, IV, 2081: "Colepius pater cunnu linget", e em 4304: "Seruilius amat nec illi sit copia/Seuil cunnulin...e", temos exemplos de homens que faziam práticas sexuais atribuídas às mulheres.

Ao analisar o contexto do primeiro século, fiz uma breve análise sobre como questões que envolvem honra e vergonha e a tradição helênica aristotélica são importantes para compreendermos o mundo das comunidades cristãs, em especial, as comunidades paulinas. Com isso, poderemos entreter como algumas imposições e posturas de Paulo, ou de uma tradição paulina, coadunavam com as estruturas que dividem o sexo num campo binário.

Masculinidades e feminilidades são discursos construídos culturalmente, pois ao mesmo tempo em que temos posicionamentos que visavam delimitar os papéis sexuais, em outros espaços, ou momentos, como nos exemplos acima, visualizamos como masculino e feminino são categorias fluídas e inseridas historicamente por questóes políticas.

\section{As Cartas Pastorais do II século}

A visão cristã inicial da Carta aos Gálatas 3,28, praticada nas comunidades de Paulo atraía para o movimento, especialmente, escravos e mulheres, mas também criava tensões e conflitos ao Ethos cultural, como no caso da comunidade de Corinto.

Certos cultos praticados nesse momento, como no caso da Grande Deusa, atraíam tanto homens e mulheres, escravos e livres, asiáticos, gregos, romanos, participavam plenamente, e num tal contexto, a confissão batismal de Gálatas não poderia ser tão 'utópica'. Contudo, uma grande diferença entre o culto público da grande deusa, no contexto das comunidades cristãs a esfera religiosa pública e a esfera privada da unidade doméstica não eram separadas. Á medida que os cristãos compreendiam em si mesmos como uma nova família, exprimindo esse auto compreensão, em termos institucionais, nas comunidades que eram no espaço doméstico. Logo, o movimento missionário cristão oferecia uma visão e uma práxis alternativas às da sociedade e da religião dominantes (ALEXANDRINA-SILVA, 2010, p. 190). 
Era um problema, principalmente para a ordem estabelecida. Além do ordenamento sobre o silêncio das mulheres inserido no texto de 1 Coríntios 14, uma boa parte da 'má reputação' dada a Paulo na questão da divisão sexual reside em declarações nas cartas 'pós-paulina'.

Compreendo pós-paulino como documentos, dentro do corpus paulinum, escritos em períodos posteriores; com isso, tenho em mente as Cartas aos Colossenses, aos Efésios e a coleção conhecida por Cartas Pastorais, 1 e 2 Timóteo e Tito. Como saíram no nome de Paulo e exerceram o papel muito marcante, ficaram conhecidas como códigos domésticos na concepção popular de sua atitude com as mulheres e prescrições morais.

A submissão à assembleia e à família é enfatizada como qualidade a ser seguida pelos membros da comunidade, em especial pela mulher. São várias as advertências, ordenando-lhes que aprendam em silêncio, com toda a submissão (2 Tm 2,11-15); ou fiquem quietas nas assembleias (2 Cor 14,34); usem o véu (1 Cor 11,02); e ainda reforçando sua submissão (Col 3,18; Ef 5,22; Tt 2,3; $1 \mathrm{Pd} 3$,1-5). Compartilho da acepção de Elisabeth S. Fiorenza ao discutir o Sitz im Leben da forma do código doméstico, com suas exigências de obediência e submissão feitas ás esposas, aos filhos e aos escravos temos que compreender que foram elaborações cristãos ulteriores advindos do código filosófico-teológico greco-romano ou judeu-helenístico (FIORENZA, 2004, p. 234).

A doutrina pós-paulina trata de um ambiente eclesial bastante posterior ao vivido por Paulo, sendo direcionadas a dirigentes individuais, e não às comunidades.

\section{Consideraçóes Finais}

Depois das explanaçóes acerca dos momentos iniciais do movimento cristão, percebe-se como o movimento liderado por Paulo foi crucial para a compreensão de uma eclesiologia; e, também, muito embora não tenham sido a grande causa da submissão e da inferioridade da mulher cristã, implicaram em bases para isto. Visto como o cristianismo pós-paulino respaldou-se no poder da figura de Paulo para legitimar a divisão sexual dentro da assembleia; definindo, portanto, feminilidades e masculinidades dentro destas antigas comunidades cristãs. E, com isso, compreendo a função dúbia e ambígua que a personagem Paulo desempenha entre os vários estudiosos e grupos atuais uma seara, ainda, perigosa e que dificilmente será um debate superado. 
Abstract: This article discusses how the discourses appropriated and selected, with the purpose of legitimizing positions and behaviors, about the Christian past, its origins, in which the corpus paulinum became a starting point for debates and discussions today. Therefore, this article suggests some different conceptions for concepts such as feminine and masculine, analyzed from a gender perspective. From this analysis emerges another look at the role of sexuality in the Pauline communities of the first century e.c., which allows a confrontation of this reading with academic discourses on the subject.

Keywords: Paul; Christianity; communities; feminine; Ambiguity; speeches.

\section{REFERÊNCIAS}

\section{Documentação Textual}

ARISTOTLES. Politics. Translated by H. Rackham. Cambridge: Loeb Classical Library, 1977.

BÍBLIA DE JERUSALÉM. São Paulo: Paulus, 1994.

JUVENAL, The Satires. With an english translation by G. G. Ramsay. London: Harvard University, 1940.

NOVUM TESTAMENTUM GRAECE. Cum apparatu critico curavit NestleAland. Stuttgat: Privilegierte Württembergische Bibelanstalt, 1993.

SALUSTIO, Catilina y Jugurta. Texto y traducción por José Manuel Pabon. (Coleccion Hispánica de Autores Giregos y Latinos). Barcelona: Alma Mater, 1954.

\section{Dicionários}

HAWTHORNE, G.F., MARTIN, R.P \& REID, D.G. (editors), Dictionary of Paul and His Letters: A Compendium of Contemporary Biblical Scholarship. Illinois: Intervarsity Press, 1993.

LIDDELL, H.G. and SCOTT, R., Greek-English Lexicon: With a Revised Supplement. Oxford: Clarendon Press, 1996.

MARTIN, R.P. \& DAVIDS, P.H. (editors), Dictionary of the Later New Testament \& Its Developments: A Compendium of Contemporary Biblical Scholarship. Illinois: Intervarsity Press, 1997.

Bibliografia

ALEXANDRINA-SILVA, R, A Ambiguidade da Ordenação Feminina: Mulher e Subjetividades nas Comunidades Paulinas nos Dois Primeiros Século. Tese defendida sob a orientação dos Professores Doutores André Leonardo Chevitarese e Pedro Paulo Abreu Funari. Campinas/SP: Unicamp, 2010.

BEAUVOIR, S. O Segundo Sexo. Belo Horizonte: Editora Nova Fronteira, 1956.

DAVIS, J., People of the Mediterranean. London: Routledge \& Kegan Paul, 1977.

DELOBEL, J., "1 Cor 11,2-16: Towards a Coherent Interpretation". In: A. VANHOYLE (org), L’Apôtre Paul (BETL 73), Lovain: University Press, 1986. 
DUNN, J. D.G., A Teologia do Apóstolo Paulo. Tradução de Edwino Royer. São Paulo: Paulus, 2003.

ERHMAN, B. D., Pedro, Paulo e Maria Madalena. Tradução de Celina FalckCook. Rio de Janeiro: Record, 2008.

ESLER, P. F. (ed.). The Early Christian World. Vol. 1. London and New York: Routledge, 2000.

FEITOSA, L. M. G. C., Amor e Sexualidade no Popular Pompeiano: Uma Análise de Gênero em Inscrições Parietais. Tese defendida sob a orientação do Prof. Dr. Pedro Paulo Abreu Funari. Canpina/SP: Unicamp, 2002, 185p.

FIORENZA, E. S. Em Memória Dela‡ As Origens Cristãs A Partir da Mulher. Tradução de João Rezende. São Paulo: Editora Paulus, 1992.

FIORENZA, E. S. Women in the Pre-Pauline and Pauline Churches. USQR, 33, 1978, pp. 153-166.

FIORENZA, E. S., A práxis do Discipulado Co-Igual. In.: HOSRLEY, R. A. Paulo e o Império: Religião e Poder na Sociedade Imperial Romana. Tradução Adail Ubirajara Sobral. São Paulo: Paulus, 2004, pp. 221-237.

HOOKER, M. D., "Authority on her head: An Examination of 1 Cor XI,10", NTS $10(1963 / 64)$ 410-416.

MACDONALD, D.R. There is no Male and Female. (HDR 20), Philadelphia: Fortress, 1986.

MALINA, B. J., O Evangelho Social de Jesus - O Reino de Deus em Perspectiva

Mediterrânea. Tradução de Luis Alexandre Solano Rossi. São Paulo: Paulus, 2004.

MEEKS, W. A., Os Primeiros Cristãos Urbanos: O Mundo Social do Apóstolo

Paulo. Coleção Bíblia e Sociologia. Tradução de I. F. L. Ferreira. São Paulo: Editora Paulus, 1992

MEIER, J. P., "On the veiling of Hermeneutics (1 Cor 11:2-16)", CBQ 40,1978, pp. 212-226.

MURPHY-O'CONNOR, J., 'Sex and Logic in 1 Corinthians 11,2-16'. Catholic Biblical Quarterly 42.4, 1980, pp. 482-500.

MURPHY-O'CONNOR, J.,"The Non-Pauline Character of 1 Corinthians 11,216", JBL 95, 1976, pp. 615-621.

NEYREY, J. H., Honor and Shame in the Gospel of Matthew. Louisville: Westminster John Knox, 1998.

PAGELS, E. H. Paul and Women: A response to recent discussion. JAAR 42, 1974, pp. 543-549.

PITT-RIVERS, J. The of the Sierra. Chicago: The University of Chicago Press, 1961.

SCROGGS, Robin. Paul and The Eschatological Woman. JAAR 40, 1972, pp. 283-303.

SHAW, T. M., Sex and Sexual Renunciation. In: ESLER, P. F. (ed.). The Early Christian World. Vol. 1. London and New York: Routledge, 2004.

SAWYER, D. F., Women and Religion in the First Christian Centuries. London, New York: Routledge, 1996. 
SCHOTTROFF, L., SCHROER, S. \& WACKER, M.-T. Exegese Feminista: Resultados de Pesquisas Bíblicas a Partir da Perspectiva de Mulheres. Tradução Monika Ottermann. São Leopoldo: Sinodal, 2008.

WEAVER, M. J., New Catholic Women: A Contemporary Challenge to

Traditional Religious Authority. Indianopolis: Indiana University Press, 1995. 